\title{
PRESENCIAS Y AUSENCIAS SUFÍES EN EL DIVÁN DEL TAMARIT, DE FEDERICO GARCÍA LORCA ${ }^{1}$
}

\author{
Juan Manuel Silva Barandica \\ Universidad de Chile \\ amacaballofat@gmail.com
}

"Ignorante del agua, voy buscando / una muerte de luz que me consuma"

Gacela XI "De la huida"

El objetivo del presente trabajo es verificar el nivel de influencia del sistema literario árabe y, más concretamente, sufí, en el Diván del Tamarit de Federico García Lorca, para intentar interpretar en ese código algunos de los poemas que demuestren con mayor claridad la aparición de figuras e imágenes de ese acervo simbólico.

Que la poesía acabe sobrepasando cualquier ademán de aproximársele más allá de las limitaciones lectoras es quizá una de las pocas certezas sostenibles en la interpretación. ¿Cómo entonces hablar sobre poesía? Ante tal pregunta, pareciera ser la vía amatoria la única solución. Amateur, amante, perseguidor de la proximidad de la figura amada que solo habrá de contentarse con un hálito, con las ruinas que han quedado de su campamento en el desierto. Y será sólo una huella, quizás, la que podrá ser leída en este doble peregrinar de poesía y lector por el desierto de las significaciones. Poesía que está en movimiento, determinando así el errar de un significado único, trascendental; y lector amante, que anhela aprehender dicha potencia, teniendo que resignarse a una leve caricia, una fugaz iluminación parecida a la esterilidad salina del lenguaje, que finalmente no será más que un sentido en la umbría senda de la interpretación. Escritura de pasos en la arena, la amada poesía, que urde el exilio del lector entre los signos gastados, para la desesperanza, para el temor a equivocarse. Y es que el real

${ }^{1}$ Trabajo presentado en la Casa Central de la Universidad de Chile en el coloquio "Federico García Lorca a 70 años de su muerte", organizado por la Facultad de Filosofía y Humanidades de la Universidad de Chile. 
error es creer en la presencia de la huella, como una verdad incontestable. Error y errar, pues solo el diálogo, la escritura sobre la escritura y la huella que intenta escuchar a la huella mientras la borra, puede dignificar y hacerle justicia a la poesía. Saber que no hay final en el laberinto de las interpretaciones significa amar, amar la poesía. Así, frente al microcosmos que plantea la escritura poética, teatral y pictórica de Federico García Lorca, es entrar, una conquista infinita, en la que solo cabe tener oídos para ver en un fulminante aparecer, el rostro de la amada entre la arena, mostrando que no es espejismo sino espejo del verdadero ser del lector apareciente.

Si bien el Diván ha sido estudiado por numerosos autores que han encontrado en él la presencia de la esterilidad, el amor homosexual y el fracaso del encuentro amatorio, es su carácter hermético, ligado a la experiencia del amor oscuro y la terrible presencia, un aspecto tratado solo tangencialmente. Más aun, las características árabes y orientales, como un rasgo del palmario hermetismo del poemario, han sido desestimadas por la crítica, como acertadamente señala Víctor de la Concha: "La cuestión del orientalismo, en sentido neto, que preocupó a la crítica quizás innecesariamente, parece hoy resuelta en sentido negativo" (365). Así, que Lorca hubiera asistido a la lectura de los Poemas arábigo-andaluces de Emilio García Gómez, además de la utilización nominal de géneros poéticos como Diván, Casida y Gacela, pareciera no tener mayor importancia. Ahora bien, intentando definir lacónicamente dichos géneros, se entiende por Diwan que: "es una palabra persa que primero designó la habitación donde los escribas hacían el inventario; más tarde denominó el libro donde se escribía. En árabe llegó a significar un cancionero, es decir, un conjunto determinado de una clase de poesías. Tamarit era el nombre de una propiedad que la familia de los García Lorca tenía en Granada (también llamada de San Vicente)" (Jofré). Asimismo, las Mu'allaqât preislámicas son técnicamente Kasidas o, como se conocerán en el período islámico, poemas largos que contienen fundamentalmente tres partes: "nasib (evocación de la amada), rahil (relato de jornadas por el desierto y las penalidades en ellas sufridas), y madih (panegírico al prócer a quien el poema se recita, y de quien se espera merced)" (Corriente 30 ). Habría que agregar que eran poemas con autoría reconocida ${ }^{2}$, de origen claramente oral, y que la "evocación de la amada" solía estar precedida por un lamento frente a las ruinas de un campamento ido, en el que ella permanecía. El carácter errante de los poetas es fundamental en el intenso nivel descriptivo, quizá primera noción formal que debería tenerse en cuenta. También interesante, el dato que dice acerca de los nómades en relación con los sedentarios, ya que "el nómada (...) es más dado a metafísica, cree en un Ser sobrenatural, inefable e inconcretable, cuya esencia sólo simbólicamente se infunde a objetos materiales" (Corriente 45-47). A partir de lo

${ }^{2}$ Llegando al punto de considerar que las Mu'allaqât, etimológicamente, habrían sido poemas ganadores de un certamen hecho en la Meca durante la peregrinación a la Kaaba; poemas que se habrían escrito en oro para ser colgados de la mezquita principal. Aunque posible, la principal etimología dice que el sentido de las Mu'allaqât es: "ganadoras". 
último, es posible desprender que la poesía árabe de las Kasidas ya tendría un sentido mistérico, escondido, ligado íntimamente al errar, al viajar. Finalmente, los Ghazales, según Hamid Ismailov provendrían del siglo noveno o décimo, llegando a consolidarse canónicamente por Hafiz (poeta iranio del siglo XIV) ${ }^{3}$. Así, Ismailov caracteriza a los Ghazales en varios aspectos: ser una forma universal, oponer centros semánticos en torno a un diálogo que va de un "yo" a un "tú", así como permitir un sinnúmero de contraposiciones en distintos niveles, llegando a conformar una estructura dialéctica, que permitiría tal flexibilidad simbólica como para hablar de lo irreal mediante lo real y de lo infinito mediante lo finito. Además, es necesario acotar que el Ghazal no tenía título y planteaba la separación entre poemas, gracias a que el autor debía incluir su nombre en el verso final. Curiosamente, Ismailov es quien plantea el conocimiento de la poesía de Hafiz por parte de García Lorca, asunto de principal importancia, considerando que también contempla como una variante de análisis del Diván, la lectura sufi ${ }^{4}$; lectura que esclarecería e iluminaría el oscuro bosque simbólico que presenta el texto. Así, para Ismailov, el amor y sus variantes en el Diván serían los nexos entre una influencia estética árabe y un sentido trascendental que comporta dicha forma poética. De esta manera, aunque no se respeten las normas clásicas de las Kasidas y los Ghazales, su inclusión conlleva la necesidad de un estudio más detallado de la profundidad de su aparecer, pues en el Diván de Lorca, la comunicación poética reviste (como en todos sus libros) un profundo sentido espiritual que, primariamente, es vinculado con su fe cristiana, pero que podría advertirse a través de esta lectura, ligado a una matriz espiritual islámica, más concretamente, sufi. Aunque es de mayor notoriedad la influencia estética $s u f i$ en el tratado de los tropos retóricos, las figuras espirituales y el tono y

3 “As is known, ghazal, as a poetic form, began forming in the ninth and tenth centuries in the Arab poetry; however, it reached perfection and, in some sense, canonization in the creative works of Hafiz" (Ismailov).

4 "And finally, this correlation allows recognizing in their foundations an artistic interpretation of Sufi philosophical elaborations, which in great detail distinguished various steps of human states and, in a mystified form, comprehended the dialectics of individual and social consciousness. After all, love in Sufism is both a means and a target for comprehending the Absolute. And the steps, such as anxiety, affection, patience, confidence, ecstasy, and dilution in the Absolute, all correlate with Lorca's series of steps. Another aspect, which we could examine separately, is an interpretation of Sufi concepts or archetypes, as it could be put nowadays, in Lorca's 'Divan', since, as we already mentioned while speaking of a classical ghazal, each term in it means not only itself but something deeper and more abstract or symbolic. Thus, a face of the beloved is the world, the beauty of the Absolute, a lock fallen on this face is the accidental world with its accidents, wine is the mystical intoxication in the unity with the Absolute, a cupbearer or a bay giving a cup is that who took the road, and so on and so forth. 'Divan del Tamarit' is also built upon these classical elements of the ghazal poetics, but their Sufi archetype interpretation is the subject of another research" (Ismailov). 
simbolismo, es menester recordar, que tanto para los místicos sufi como para Lorca, la utilización formal de ciertos procedimientos e imágenes no es parte de un nivel ornamental sino, por el contrario, del mismo sentido velado y cubierto por ella. En la poesía lorquiana, el nivel superficial es parte de la interioridad central, así como en la nuez, la cáscara participa de su condición seminal.

Dentro de los escasos datos del origen sufi, se encuentran señales de que esta doctrina hermenéutica, práctica, poética y devocional, sería anterior al islam, situación que, según Jean Chevalier, no se opondría a la concepción de que el sufismo es el corazón del islam. Como interiorización y profundidad del discurso coránico, el sufí encontraría su lugar en una cadena iniciática de fe desde la aparición del profeta. En ese sentido, una de las máximas de esta mística o disciplina experiencial de la divinidad es ascender desde el texto coránico, pasando por el profeta, hasta llegar a Allah. Así, todos los caminos del sufí islámico (islam: sumisión) deben conducir a la divinidad; por eso tal es la complejidad del análisis de esta potencia espiritual histórica y transhistórica a la vez.

Otro aspecto relevante es el que hace referencia al nivel de praxis del sufi; esto, pues hay que entender que el sufi es, por completo, un ser de experiencia. Por esto, muchos sufíes han renegado de la teorización, para abocarse de lleno a su proceso de autoconocimiento; proceso que llevará, estadio tras estadio, a una progresión de pasos y medidas ligadas al estudio de sí mismo (y del Corán, ya que muchos sufíes han considerado al Libro, como el nivel más alto de praxis, aquel en el que Dios mismo desciende en sus niveles más profundos a encontrarse con el alma humana), a alcanzar una real hermenéutica del ser ${ }^{5}$. Ahora bien, el nivel escritural de los sufíes es relativo, ya que hay casos (como el de Rumi, poeta persa del siglo XIII) en el que los discípulos copiaban los dichos del maestro, mientras que otros, como el gran maestro Ibn Arabi de Murcia, dedicaban su tiempo al estudio y a la escritura. Del mismo modo que en el judaísmo, en el islam la palabra es sagrada, siendo vehículo por naturaleza del doble nivel esotérico-exotérico de la mayoría de los monoteísmos. Así, sinagogas y mezquitas, como ejes de contacto entre la tierra y el cielo, resisten la idolatría y la representación antropocéntrica, adornando devocionalmente sus "hogares espirituales" con los suras del Corán o algunos pasajes de la Torah. No es casual esto, ya que el lenguaje sagrado interpela al vulgo con la fe, protegiendo la divinidad para la lectura interna, la experiencia del lenguaje sagrado, experiencia que, en los sufies, se logra mediante la repetición rememoradora o Dikr. Por consiguiente, aunque haya una ausencia de Dios en la palabra, la presencia del lenguaje sagrado es una promesa para el sufí, la condición de reencuentro con la divinidad:

“«Hazme entrar, oh Señor, en las profundidades del Océano de tu unidad infinita»: tales eran las palabras con las que empezaba una oración que acostumbraba a decir

5 "El sufismo implica toda una hermenéutica, un arte de interpretar la palabra por la experiencia y la experiencia por la palabra" (Chevallier 203). 
el gran sufí andaluz Muhyi-1-Din Ibn Arabi; y en sus tratados, los sufíes han hecho siempre repetida mención de ese «Océano» que servía también de referencia simbólica al término hacia el que su camino les conducía. Sobre la base de este símbolo y como respuesta a la pregunta: « ¿qué es el sufismo?» empezaremos, pues, por decir: de vez en cuando, una Revelación «fluye» como una marea procedente del Océano de Infinitud hacia las costas de nuestro mundo finito; y el sufismo es la vocación, la disciplina y la ciencia que permiten sumergirse en el reflujo de una de esas olas y ser devuelto con ella a su Fuente eterna e infinita" (Lings 29).

Asimismo, es pertinente recordar la valoración del agua en el mundo árabe, tanto como una manifestación de la divinidad, como el camino de regreso a ella ${ }^{6}$. De esta forma, el sufismo, con sus influencias gnósticas, persas, neo-platónicas, herméticas e incluso hindúes, busca además, una rememoración de la presencia-ausente de Allah en el propio individuo, así como también, el descubrir el verbo encarnado, la asunción de la realidad trascendental, verdadera, en la propia experiencia devocional-meditativa-poética.

Por otra parte, este "regreso" a la realidad verdadera divina toma la forma de un ahogarse $\mathrm{p}^{7}$ (fundamental en Lorca), también comprendido como aniquilamiento: "Lo que buscan es, por emplear otro término sufí, la extinción (fâna') de lo creado en lo Increado, de lo temporal en lo Eterno, de lo finito en lo Infinito; y, para algunos sufíes, la recitación del Corán ha constituido, durante toda su vida, el principal medio de

6 "El Islam reivindica la restauración del monoteísmo de Abraham, cuyo hijo primogénito, Ismael, es considerado el patriarca de los árabes. En efecto, el advenimiento del Islam está misteriosamente prefigurado y predicho por la historia escrituraria de Agar y su hijo Ismael, cuando fueron expulsados al desierto. El extravío de Agar y su hijo simboliza el politeísmo preislámico de los árabes; «cuando se acabó el agua del odre», la Tradición monoteísta de Abraham, transmitida por Ismael a sus descendientes, murió. Agar, imagen del «genio» o del alma colectiva de las tribus árabes, al encontrarse frente a la agonía espiritual de éstas - de la «muerte de su hijo»- «alzó la voz y lloró». Pero fue la «voz del niño» la que «Dios oyó», la llamada interior de ese descendiente tardío de Ismael que personificó el espíritu puro de los árabes: Mohammed. Lo Absoluto tuvo sed de Sí mismo, y de Su sed sin límites hizo a aquel hombre del que hubo de brotar la fuente viva de la Unidad divina en el desierto del alma árabe: «y vio un pozo de agua», el Islam o el monoteísmo abrahámico, resucitado y readaptado a las condiciones cíclicas de los «últimos tiempos». «Dio de beber al chico...»: la comunidad musulmana atrajo desde aquel momento la Irradiación salvadora del Uno sobre todos cuantos siguieron al Profeta en «la sumisión (a la Voluntad divina)» (al-islâm); y «Dios fue con el niño, que creció...»: fue con la nueva religión, que integró a una gran parte de la humanidad en su afirmación ardiente del Único" (Schaya 4).

7 "Los sufíes hablan de «tratar de ahogarse» (istigrâq) en los versículos del Corán que, según una de las más fundamentales doctrinas del Islam, son la Palabra increada de Dios" (Lings 15). 
concentración en Dios, lo que es la esencia misma de todo camino espiritual" (Lings 15). Aniquilación, pues la única verdad, la única luz, está escondida en una noche oscura $^{8}$. Es el viaje nocturno del Profeta, la matriz arquetípica del viaje sufí hacia la luz. Y ya el viaje espiritual ${ }^{9}$, uno de los sentidos más profundos de esta mística. Todo es vanidad e ilusión, y no se ha salido del desierto ni del exilio espiritual ${ }^{10}$. Esa es la esencia de la guerra santa, la batalla librada contra el alma para salir del desierto y las falacias; el lóbrego sendero que, si bien está encadenado a una tradición y a una transmisión de maestro a discípulo, debe realizarse en soledad: "El desconocido personaje que guía a Moisés desempeñará un papel considerable, con el nombre de al-Khidr o Khadir, en toda la historia del sufismo, como el iniciador, el santificador, el guía, superior a los profetas" (Chevalier 42-43). Así, el Khadir es el maestro espiritual invisible, el médium directo con la divinidad, que conduce al correcto y justo al camino necesario para alcanzarla. De esta manera ocurrió con Ibn Arabi, quien recibió varias veces la visita de este maestro. Por ende, al igual en la Cábala judía, hay tanto una búsqueda individual y colectiva, como un llamado de la divinidad misma al sujeto, para que, como su nominación etimológicamente presupone, sea sujeto a ella: lo que un sujeto ama, debe amarlo también para que éste se vuelque en su búsqueda. Finalmente, al igual que en la mística cristiana, los niveles purgativo, iluminativo y unitivo son considerados como estadios de perfección y de aproximación a la verdad revelada. Así, los procesos de elevación espiritual encuentran su realidad poética en cada uno de estos estadios, idea pertinente para adentrarse en el análisis del Diván lorquiano, como un texto iluminativo-purgativo, en el que quizás haya existido una voz poética guía, como el Khadir o el Duende, para adentrarse en un viaje del alma al encuentro de las

8 “Esta mención del último Día recuerda que, como el Corán, el Profeta está «obsesionado» por la Hora; y esta «obsesión» no puede disociarse de uno de los acontecimientos fundamentales de su misión, el Viaje nocturno, también llamado, según su principal episodio, la Ascensión" (Lings 22).

9 “El sufismo representa este proceso transformante como un viaje: el corazón del viajero espiritual recorre una progresión ascendente de moradas o estaciones cualitativas que culminan con la realización de aquella morada que ya no es una morada pues no tiene un atributo particular que la caracterice: La Estación de la no estación (maqâm lâ maqâm)" (Beneito XV).

10 “Al ser el hombre un exiliado, un centro espiritual simbolizará más eficazmente la patria si no le resulta inmediatamente accesible. Esta es, sin duda, una de las razones por las que, en La Meca, en los albores del Islam, la oración se realizaba en dirección a Jerusalén. Pero si el hombre es un exiliado en primer lugar en razón de su existencia separada de Dios, en segundo lugar lo es por su caída del Paraíso. Deben, pues, efectuarse dos retornos al hogar, y sin duda es en razón del segundo exilio del hombre por lo que, en el Viaje nocturno, el Profeta fue primero transportado «horizontalmente» de La Meca a Jerusalén antes de su Ascensión «vertical», de manera que su viaje pudiese ser el prototipo perfecto del camino que deberían seguir los avanzados de entre su pueblo" (Lings 24). 
fuerzas inefables que existen como una historia de la lengua en el lenguaje poético, que no es más que otro modo de advertir la presencia-ausencia de una entidad superior, unívoca y siempre en fuga.

Relacionando la ausencia-presencia de un significado o divinidad en fuga con la escritura del Diván, el principal movimiento dialéctico, o motor dialéctico en su nivel tropológico, es la Alusión. Figura retórica que media entre la metáfora, metonimia, prosopopeya y comparación (entre otras) en el texto. Ahora bien, según Ibn Arabi ${ }^{11}$, tal mediación sería en sí dialéctica, ya que permitiría un ocultamiento de la verdad al impío, así como un desocultamiento de dicha verdad al justo, siendo así, un re-velar: movimiento que oculta, muestra y vuelve a ocultar en la presencia furtiva. De esa forma, tal significación tendría su correlato en la huida de lo amado, como modelo configurador de la realidad en el poemario. Además, el hecho de que la geografía del poema sea Granada y, principalmente, el Tamarit, como una propiedad familiar, íntima, genera que la Alusión como mediador del sentido latente o subterráneo, destruya prácticamente todo vínculo con una referencia anterior, ya sea por símil u oposición (metáfora-ironía), dejando en una orfandad de significado, casi hermético, al texto. Como antes se recalcó, esta es la dimensión del Diván: una fuga del significado, una caída libre en las posibilidades de la significación, así como también, el hecho de considerar al lenguaje poético mismo como una cubierta o umbral, como un símbolo ${ }^{12}$

\footnotetext{
11 "Conocer la alusión

es tanto un acercarse

como un distanciamiento;

y el movimiento que genera en ti

es este viaje diurno de retorno,

la incesante andadura de la noche.

Búscalo bien, pues Dios

lo ha transformado para así ocultarlo

de aquel en quien mentira y extravío

a la par se manifiestan.
}

Es esto una llamada de atención

sobre la inmunidad

de aquel a quien Dios dijo:

« ¡Sé pues!, e incorporose a la existencia

como ser engendrado

de lo cual son los hombres de la Vía

verídicos testigos».

Ibn Arabi «La alusión»"

(Autores Varios 42).

12 "Si nos referimos al arte sagrado es porque suministra un ejemplo inmediatamente manifiesto de la compatibilidad entre lo universal y lo particular. La misma compatibilidad aparece en el simbolismo del círculo con su centro, sus radios y su circunferencia. La palabra 
(aunque no haya una mismidad entre símbolo y lo simbolizado, aunque en el símbolo esté ausente su detrás) hacia un espacio inefable, quizá divino. Por eso, la familiaridad devastada, conduce a la paradoja bio-bibliográfica del poeta, para quien Granada y Andalucía, era el lugar del sentido. En este caso, es la entrada y el marco no-verosímil a una meditación dinámica acerca de la poesía, el amor y la trascendencia. En el Tamarit, los animales, las plantas, las construcciones, los ciclos temporales, los astros, las personas y los elementos, parecieran revelarse contra el sentido cotidiano que se conoce de ellos. Sin llegar a una lectura vanguardista (como se ha querido proponer), en este caso la propuesta es que hay un acervo espiritual en Lorca, que tendría como eje la confluencia islámica, judía, cristiana, gitana y pagana, y que encontraría como piedra de toque, las lecturas de los Poemas arábigo-andaluces, además del conocimiento de la poesía de Hafiz. En ese sentido, versos como "Ignorante del agua, voy buscando / una muerte de luz que me consuma", así como "Bajo las rosas tibias de la cama / los muertos gimen esperando turno" pueden ser leídos intentando otorgarles un sentido cotidiano, pero no si no es menester de este trabajo, el comprobar que hay una raíz ilógica (amarga) en niveles subterráneos de la estructura de los poemas, que es asimilable por el tono arábigo del poema, las matrices discursivas genéricas y las constelaciones simbólicas trascendentales, a una búsqueda mística en torno a la poesía misma, Dios o el más allá, estableciendo así una nueva lectura que no hace más que unirse al coro de lecturas anteriores. Por consiguiente, la presencia-ausencia de la Alusión, como el común denominador tropológico del poemario, conduce a pensar que ninguno de los elementos son accesorios, así como ningún verso o palabra deja de esconder un misterio que ha sido escondido o desconocido por el propio poeta, en una búsqueda de la luz, de la iluminación, en la que cada poema es un estadio o vía de acceso diferente e igualmente valioso para comprender lo inefable subyacente a la letra escrita.

Para lograr observar y comprender la aparición de una figura o imagen sufi en el Diván, se ha escogido arbitrariamente el agua. De tal modo, "Eso que, mediante la realización espiritual, es devuelto a la Fuente, puede ser designado como el centro de conciencia. El Océano está tanto dentro como fuera; y el camino de los místicos es un despertar progresivo, como si se «reculase» en dirección a la raíz del propio ser; es un recuerdo del supremo Sí que trasciende infinitamente al ego humano y que no es otra cosa que las profundidades hacia las que la ola refluye" (Lings 5). Así, la figura del

«simbolismo» se utiliza aquí para indicar que el círculo es considerado no como una imagen arbitraria, sino como una forma enraizada en la realidad que tal imagen ilustró, en el sentido de que debe su existencia a esa realidad, de la que, de hecho, es una prolongación existencial. Si la Verdad no irradiara, no podría existir nada comparable a un radio, incluso en el sentido geométrico, sin hablar del camino espiritual del que constituye el ejemplo más elevado; todos los radios desaparecerían de la existencia, y con ellos el mismo universo, porque la forma radial es uno de los más grandes símbolos: simboliza aquello de lo que todo depende, es decir, la conexión entre el Principio divino y sus manifestaciones o creaciones" (Lings 11). 
despertar es una forma de búsqueda acuática ${ }^{13}$ de lo perdido, aquello anhelado, el objeto del amor. Es la aniquilación, la interiorización y, más precisamente, un perseguir esa reabsorción de las potencias del agua, luego del peregrinar por el desierto: "por citar a un sufí del siglo pasado (el šayj al-Darqaw'), "como el que busca agua cavando un poco por allí y un poco por allá; no encontrará agua y morirá de sed, mientras que el que cava en un solo lugar, confiando en Dios y dejándolo en Sus Manos, encontrará agua; beberá y hará beber de ella a otros»" (Lings 12). Este desprendimiento que no es más que un viaje al fondo de la noche oscura del interior, es también la búsqueda de un beso ${ }^{14}$, del océano y el agua salutífera en que los contornos y límites se ven reducidos al uno, al espacio del no espacio, al más allá en el concilio de las fuerzas sexuales y motoras que disponen las distancias, la infertilidad, el desencuentro y el vacío del que hablan las flores cortadas, los animales desangrados y las ciudades desiertas en el Diván. Y es que el mundo objetivo en el poema no es más que una hipóstasis de los conflictos espirituales, de la guerra santa contra el enemigo del alma. Por eso, los niveles descriptivos y apelativos del Diván, parecieran mostrarse destrozados: es Granada el alma del poeta, y es ella misma el campo de batalla para mostrar ese amor que conduce al agua germinal, que lleva al vaciamiento de las formas eclipsadas, que conduce a ahogarse en la materia inmutable. Así, Heráclito refiere, en una influencia espiritual anterior al sufismo, la transformación de la materia en esencia: "Para las almas la muerte consiste en volverse agua, para el agua es muerte volverse tierra; mas, a la inversa también, de tierra se hace agua, y de agua, alma" (García Bacca 242) ${ }^{15}$.

El agua, entonces, es una de las máximas condiciones sufí en el Diván; sin ella no se explicaría el factor paradisíaco de Granada para el poeta (así como para el errante magrebí), así como la condición desierta del espíritu. También importante, el hecho que tanto el niño ${ }^{16}$ como la mujer tendida (análoga a la muchacha en el agua), respectivamente el guía del errante y la presencia divina (sekiná) comprendida como el espacio paradisíaco del reencuentro y la conciliación con el significado o Dios, necesiten de un fluir acuático, de una profundidad numerosa, en la cual hallar la restitución de su origen y sentido primario absoluto.

13 "Como se sabe, el agua circula en la Alambra, dentro de los edificios y fuera de ellos. Es, pienso, la nostalgia del agua que se apodera de aquellos que vienen del desierto" (Arteche 249).

14 "No le temo al océano de la muerte, en que todo se acaba. La rosa de tu boca es el centro del mundo" (Hafiz 72).

${ }^{15}$ Juan David García Bacca (trad. y ed.) Los presocráticos. México, Fondo de Cultura Económica, 1991.

16 "El sueño que ansía es de frescura; al cortar su corazón, su centro y caer al mar reingresa al espacio del origen y la re-creación" (Jofré). 
En la Gacela V "Del niño muerto", el infante mistagogo es un nuncio de la muerte, es un vórtice con el más allá: "Tu cuerpo, con la sombra violeta de mis manos / era, muerto en la orilla, un arcángel de frío" (García Lorca 119). Es el arcángel purpúreo en el umbral del alba acuática, en el espacio intermedio, traduciendo en mudez de infante la experiencia iniciática del agua, del paso del líquido dulce al salado, del paso de las entidades eclipsadas, a la consolidación de la Luz. Y no hay acceso a ella, más que en un presentimiento, en una conjura de elementos (revoluciones solares: niño, perros: custodios del umbral, lirio: flor acuática que convive entre el cielo y la tierra, abriéndose hacia la luz y profundizando en la intensidad del agua) que llevan al vino, a la sangre transubstanciada que provoca la embriaguez espiritual. Pues "Todas las tardes en Granada, / todas las tardes se muere un niño" (García Lorca 118) y es ese niño el crepúsculo en el que el sujeto enunciante quiere entrar para el fin de las mutaciones, para el fin de la luz falsa, para poder entrar en la purificación antes del alba.

En la Gacela VII "De la muerte oscura", el niño es el guía al que quiere seguir el sujeto enunciante. Quiere seguirlo más allá del pecado y la serpiente, más allá de la muerte que engendra vida en la materia, de la muerte que pudre los cuerpos, dejando lamento, nostalgia y vacío. Quiere entrar al sueño (el centro de las figuras oníricas sería un océano de imágenes primordiales) del agua, no a la sangre de los muertos, sino al fin de la muerte; es la muerte del morir, el avance purificador por el desierto de alacranes, por la aurora velada en una noche sin fin. Quiere dormir el sueño de las manzanas, para volver la historia del pecado y la degeneración espiritual, a su punto de entrada, al umbral del paraíso, en el que el niño debe dejar de ser "yo", dejar de ser corazón, centro, individuo y receptáculo del vino sombrío de la vida material (que es la sangre), para fundirse en la totalidad sin más unicidad que la del creador, o el significado preexistente al ente: el sujeto enunciante. Aun así, la unión no es completa, y el nuncio del océano de Allah o el significado, se ha perdido sin que nadie lo siga. Y es solo el recuerdo, la rememoración (Dikr) de su existencia, un vehículo para encontrar el valor y dejarlo todo, uniéndose en él.

En la Gacela X "De la huida", el sujeto busca al niño espiritual (Khadir) que lo haga reencontrarse con el océano divino. Pues se ha perdido muchas veces en el mar, y es solo el mar físico el que le recuerda el vacío, la posibilidad de perderse en el pletórico otro. Así, el corazón del niño es el centro que habrá de destruirse, de aniquilarse en el agua, por eso el sujeto melancólico busca en la profundidad de las raíces el manantial secreto y puro que pueda llevarlo al océano del significado. Por eso rechaza al hueso, pues su blancura es fatua; además, su ignorancia del agua no impide que comprenda al beso como el vínculo del vacío, de la pérdida de la individualidad, en la dirección de esos niños secretos que en su justicia del alma, desaparecen en cada uno de los vórtices que unen la materia con su exterminio. Ahora bien, el vacío del beso, la imposibilidad de fundirse en el otro más que por un orificio, es su revés. Como las flores cortadas, las entidades pierden la capacidad de ser llenas de jugos y polen, y en su propia devastación muestran la perplejidad espiritual del enunciante, así como la vía de acceder a los pasos del niño: el océano como una muerte de luz que lo consuma.

En la Casida I "Del herido por el agua”, es evidente la progresión en el agua genésica y divina. Pues el descenso al pozo está ligado al surtidor de los sueños que defiende al 
niño de las algas. Y es el descenso al pozo, un introscender ${ }^{17}$, un alcanzar la fibra última de la identidad, ya condensada en la identidad divina; como en un principio gnóstico: descubrir al Dios interno es descubrir al Dios absoluto. Esto, sin subjetivizar la experiencia divina, ya que el niño, como el mensajero de la mudez, es el peregrino que es llamado por el agua para volver a su hogar. Y es el pozo del vacío el que es llenado por un agua de las profundidades, como en la fuente del paraíso. Así, debe atravesar los desiertos abrasadores del alma, en un amanecer que nunca sucede más que en la fantasmagoría de los astros sucedáneos. Y es, finalmente, la voluntad del enunciante la que lo lleva a querer perder el corazón (como el niño en alta mar) en el hambre de las algas y entidades que protegen el paso de la vida a la muerte o, en un sentido sufí, a la renuncia de la renuncia.

En la Casida II "Del llanto", es posible descubrir que el agua que cae de las nubes es análoga a la lágrima que cae de los ojos. Es una purificación del alma, es una alianza entre Dios y el hombre. Así "¡Oh lluvia divina! Borra mis iniquidades, pues en el libro en que se inscriben nuestros actos las letras de mi nombre están trazadas en negro" (Hafiz 85). Y es en el llanto el agua salada que mana por los astros verdaderos del cuerpo, el instante en que lo alto del cuerpo se comunica con lo bajo. Ahora bien, los niveles de purificación de la lluvia son: comunicativos, protectores y guías, y unitivos. Pues el ángel es el portador del mensaje, el perro (a pesar de su connotación de carroñero y desenterrador de los muertos) es el protector del pórtico hacia el más allá, además de su guía; mientras que la música del violín es el agudo afán de una saeta que deja el ojo llagado por Dios, provocando la unidad experiencial. En ese sentido el llanto, condicionado o no por la melancolía o el desamparo, es la música que promete la unión.

En la Casida VII "De la muchacha dorada", es la presencia de la sekiná o aparición de Dios en la materia que intenta salir del agua divina impregnando desde la interioridad del mundo físico, es decir, su significado ausente o Dios en fuga, la superficie del agua. Pero son los animales del umbral, los anfibios y las algas, los que ensombrecen en su calidad de intermediarios, la áurea revelación de la divinidad en el espacio. Así, la noche lunada en su forma de espejo de un sol (que a su vez, es espejo de las emanaciones de Dios) ensombrece su iluminación. Por consiguiente, la impotencia del súbito advenimiento se carga en las transiciones al alba falsa, al frío de las distancias, frente a un tiempo eterno siempre vivo y detenido que es la propuesta regeneradora de la sekiná. Finalmente, la muchacha con la purificación de la lágrima, para el duelo universal de la materia, es despedida por el cantor y el intérprete de la voz divina: el ruiseñor, quien en su sitial preferencial, arde en llamas al contacto purificador de la lágrima divina, viendo cómo la intención del creador se ve frustrada al desaparecer la muchacha en la profundidad, siendo el agua, en una mezcla del alba velada y del influjo de la propia muchacha, el último espectador de la tragedia.

${ }^{17}$ Trascender hacia dentro, hacia el interior. 
Al cabo, habiendo intentado mostrar la aparición de ciertas presencias-ausencias en busca de una interpretación más profunda, que hiciese justicia a la oscuridad del Diván desde el imaginario sufí, no es posible demostrar más que una posible iluminación. Asimismo, aunque no se logre identificar a lo Amado (como lo hicieran Böhme, Eckhart, San Juan de la Cruz, Santa Teresa de Ávila y otros), la búsqueda poética da pautas que elevan la escritura a un nivel místico, metafísico introspectivo, espiritual y esotérico, que, si bien no puede dar cuenta más que de un supuesto relampagueo, no requiere de la unión balbuciente y extática, pues ya ese ámbito escapa al verso y la traducción, como una palabra increada, como un océano infinito que solo es alcanzable desde la vida: Poesía Amada en el desierto, que seguirá escapando a la escritura del amante.

\section{BIBLIOGRAFÍA}

a) Básica

García Lorca, Federico. "Entrevista del caricaturista Bagaría a Federico García Lorca (fragmento)". Diván del Tamarit. Santiago: Nascimento, 1979. 96-101.

Poeta en Nueva York-Diván del Tamarit - Seis poemas galegos. Barcelona: R.B.A., 1998. 95.

b) Crítica lorquiana

Alonso, Dámaso. "Federico García Lorca y la expresión de lo español”. Poetas Españoles Contemporáneos. Madrid: Gredos, 1958. 271-280.

Arteche, Miguel. “Lorca: Paraíso y Babilonia”. Poesía y Prosa. Santiago de Chile: Universitaria, 2001. 247-263.

Cernuda, Luis. Estudios sobre poesía española contemporánea. Madrid: Guadarrama, 1957.

De la Concha, Víctor. "Poesía de la generación de 1927: Federico García Lorca, Rafael Alberti”. En Francisco Rico (Ed.): Historia y Crítica de la Literatura Española. Época Contemporánea: 1914-1939. Barcelona: Crítica, 1984.

Díaz Plaja, Guillermo. Federico García Lorca: un estudio crítico. Buenos Aires: Kraft, 1948.

García Posada, Miguel. "Notas al Diván del Tamarit". Poeta en Nueva York- Diván del TamaritSeis poemas galegos. Barcelona: R.B.A., 1998. 131-140.

"Poesía de la generación de 1927: Federico García Lorca, Rafael Alberti". Historia y Crítica de la Literatura Española. Época Contemporánea: 1914-1939. Ed. Francisco Rico. Barcelona: Crítica, 1984. 351-373.

Glisser, María Esther. "Estructura de la Gacela del Amor Desesperado y de la Casida de la Mujer Tendida". Diván del Tamarit de García Lorca. Santiago: Nascimento, 1979. 3376.

Ismailov, Hamid. "On the poetics of Lorca's Divan of Tamarit". Traxoniana Journal de Estudios Orientales. Diciembre $2003<\mathrm{http}$ ///www.transoxiana.org/0107/ismailovdivan_tamarit-en.html> 
Jofré, Manuel. "Lectura de Diván del Tamarit de Federico García Lorca (1898-1936)". Literatura y Lingüistica [online] 11 (1998): 75-83. 12 de septiembre de 2007. <http:// www.scielo.cl/scielo.php?pid=S0716-58111998001100006\&script=sci_arttext $>$

Martínez Nadal, Rafael. "El último Lorca: amor y muerte". Historia y Crítica de la Literatura Española. Época Contemporánea: 1914-1939. Ed. Francisco Rico. Barcelona: Crítica, 1984. 402-405.

Schonberg, Jean-Louis: Federico García Lorca. El hombre-la obra. México: Cía. Gral. de Ediciones, 1959.

c) Sufismo y arabismo

Autores Varios. La taberna de las luces. Poesía sufi de al-Andalus y el Magreb (del siglo XII al siglo XX). Trad. Pablo Beneito. Murcia: Editora Regional, 2004.

Beneito, Pablo (trad.): "Prólogo" La taberna de las luces. Poesía sufi de al-Andalus y el Magreb (del siglo XII al siglo XX). Murcia: Editora Regional, 2004. P. XI-XXI.

Burckhardt, Titus. Esoterismo Islámico. Introducción a las doctrinas esotéricas del Islam. Madrid: Taurus, 1980.

Chevallier, Jean. El Sufismo y la tradición islámica. Barcelona: Kairos, 1986.

Corriente Córdoba, Federico. Las Mu'allaqât: Antología y panorama de Arabia preislámica. Madrid: Instituto Hispano-Árabe de Cultura, 1974.

Hafiz. Los Gazales de Hafiz. Madrid, Visor, 1981.

Lings, Martin. ¿Qué es el Sufismo? Euskalnet, archivo de material islámico Junio 2007 $<$ http://www.euskalnet.net/graal/index7.htm>

López Baralt, Luce. "Los moriscos y el siglo de oro.” Web Islam Junio $2007<$ http://www. webislam.com/?idt=955>

Schaya, Leo. La doctrina sufi de la unidad. (Disponible en página web) Euskalnet, archivo de material islámico. Junio 2007. <http://www.fortunecity.es/banners/interstitial.html? http://members.fortunecity.es/chefo/sufi1.zip>

Yal al-Din Rumi. Poemas Sufies. Madrid: Hiperión, 1997.

Palabras clave: García Lorca, Diván del Tamarit, sufismo.

KEY WORDS: García Lorca, Diván del Tamarit, sufism. 